\title{
Large-Scale Surface Mass Balance of Ice Sheets from a Comprehensive Atmospheric Model
}

\author{
Lennart Bengtsson • Symeon Koumoutsaris $・$ Kevin Hodges
}

Received: 24 July 2010/ Accepted: 15 March 2011/Published online: 20 April 2011

(C) Springer Science+Business Media B.V. 2011

\begin{abstract}
The surface mass balance for Greenland and Antarctica has been calculated using model data from an AMIP-type experiment for the period 1979-2001 using the ECHAM5 spectral transform model at different triangular truncations. There is a significant reduction in the calculated ablation for the highest model resolution, T319 with an equivalent grid distance of ca $40 \mathrm{~km}$. As a consequence the T319 model has a positive surface mass balance for both ice sheets during the period. For Greenland, the models at lower resolution, T106 and T63, on the other hand, have a much stronger ablation leading to a negative surface mass balance. Calculations have also been undertaken for a climate change experiment using the IPCC scenario A1B, with a T213 resolution (corresponding to a grid distance of some $60 \mathrm{~km}$ ) and comparing two 30-year periods from the end of the twentieth century and the end of the twenty-first century, respectively. For Greenland there is change of $495 \mathrm{~km}^{3} /$ year, going from a positive to a negative surface mass balance corresponding to a sea level rise of $1.4 \mathrm{~mm} /$ year. For Antarctica there is an increase in the positive surface mass balance of $285 \mathrm{~km}^{3} /$ year corresponding to a sea level fall by $0.8 \mathrm{~mm} /$ year. The surface mass balance changes of the two ice sheets lead to a sea level rise of $7 \mathrm{~cm}$ at the end of this century compared to end of the twentieth century. Other possible mass losses such as due to changes in the calving of icebergs are not considered. It appears that such changes must increase significantly, and several times more than the surface mass balance changes, if the ice sheets are to make a major contribution to sea level rise this century. The model calculations indicate large inter-annual variations in all relevant parameters making it impossible to identify robust trends from the examined periods at the end of the twentieth century. The calculated inter-annual variations are similar in magnitude to observations. The 30-year trend in SMB at the end of the twenty-first century is significant. The increase in precipitation on the ice sheets follows closely the ClausiusClapeyron relation and is the main reason for the increase in the surface mass balance of Antarctica. On Greenland precipitation in the form of snow is gradually starting to decrease
\end{abstract}

L. Bengtsson $(\bowtie) \cdot$ K. Hodges

Environmental Systems Science Centre, University of Reading, Reading, UK

e-mail: lennart.bengtsson@zmaw.de

L. Bengtsson · S. Koumoutsaris

International Space Science Institute, Hallerstrasse 6, 3012 Bern, Switzerland 
and cannot compensate for the increase in ablation. Another factor is the proportionally higher temperature increase on Greenland leading to a larger ablation. It follows that a modest increase in temperature will not be sufficient to compensate for the increase in accumulation, but this will change when temperature increases go beyond any critical limit. Calculations show that such a limit for Greenland might well be passed during this century. For Antarctica this will take much longer and probably well into following centuries.

Keywords Mass balance $\cdot$ Ice sheets $\cdot$ Greenland $\cdot$ Antarctica $\cdot$ Atmospheric models

\section{Introduction}

The ice sheets on Antarctica and Greenland are exposed to a number of processes on a variety of time scales. These include long-term adjustments over millennia and fast changes driven by ice-dynamics related to processes in grounding lines or calving fronts. Several of these processes are incompletely understood. The net contribution to sea level change is a very complex process that requires a long-term integration including realistic, high-resolution land-ice models. However, in this study we restrict the investigation to the surface mass balance, SMB, and in particular how SMB is expected to change in a warmer climate. We determine the change in SMB from the difference in mass that is gained from solid precipitation and the losses that come from evaporation, sublimation or direct run-off of water. Consequently, we will ignore losses due to calving, as this has to be calculated using a dynamical model of the complete land ice. It has been suggested that the mass losses on Greenland due to calving is of the same order as SMB (Lemke et al. 2007; IPCC AR4). For Antarctica, on the other hand, iceberg calving or episodic losses of large part of the ice shelf are the overall dominating mechanisms for mass losses.

The sink terms are or the ablation is generally well estimated from routine meteorological observations such as surface temperature, cloudiness, etc., but the source term of solid precipitation requires the knowledge of the three-dimensional atmospheric circulation and is generally more difficult to estimate. There are several reasons for this. Firstly, precipitation varies widely in time and space and available observations, such as those that exist on the ice sheets, are insufficient to provide a satisfactory sampling. Secondly, precipitation is extremely difficult to measure accurately due to wind and similar problems making it difficult to accurately collect snow in the precipitation gauges (Bromwich et al. 2004). Generally there is a considerable underestimation of snow (Groisman et al. 1999; Allerup et al. 2000). Estimates from snow on the ground are also unreliable for several reasons including the problem with snowdrift leading to a very uneven deposition.

Precipitation on the Greenland ice sheet falls essentially as snow except in coastal regions. Over Antarctica practically all precipitation comes as snow. This is also likely to occur even if the climate is warming by some degrees Celsius towards the end of this century as suggested from the IPCC model simulations (Lemke et al. 2007; IPCC AR4). Even if precipitation occasionally comes as rain it is likely to subsequently freeze as the water percolates into the depth of the ice.

Simulation of the surface mass balance of glaciers and ice sheets has therefore been struggling with the difficulty of estimating precipitation (Oerlemans 1990) and in particular to estimate how future precipitation will evolve in conditions of higher surface and tropospheric temperatures. The methodology that has evolved during the last decades (e.g. Ohmura et al. 1996) is to make use of weather prediction models or similar models used for climate simulation. The principle is simple. The model calculates the temperature and the 
surface energy balance from which the mass changes can be calculated. The net mass balance is obtained from the model's calculation of solid precipitation minus the net loss from melting and sublimation/evaporation. In the case of rain, the water is assumed to be drained away but might refreeze if percolated into the depth of the land ice. However, the refreezing is not normally considered in these kinds of studies and will not be included here.

As atmospheric models have improved in resolution and the handling of physical processes such as clouds, convection and radiation, they have increasingly been used to estimate the surface mass balance. The calculation of precipitation cannot be made from initial data but requires a short-time integration to avoid adjustment problems (Bengtsson et al. 2007b). Alternatively, one might also calculate the net divergence of water vapour over a region covering the ice sheets. Such estimates have been undertaken with increasingly realistic models during the last decade (Serreze et al. 2006; Jakobson and Vihma 2009). The advantage with this approach is that it can be calculated directly from analyses of horizontal winds and water vapour.

In a warmer climate the net water vapour transport increases rapidly as it scales with the Clausius-Clapeyron $(\mathrm{C}-\mathrm{C})$ relation as will be outlined below, the reason for this unexpected consequence, that will significantly influence the SMB, is the circumstance that different physical processes regulate the change in atmospheric water vapour and the change in evaporation. As a consequence, water vapour is expected to increase more rapidly than evaporation and consequently also faster than the global precipitation. Following the $\mathrm{C}-\mathrm{C}$ relation the increase is some $6-7 \%$ for each degree of warming, while global mean precipitation increases only by about $1 \%$ per degree warming (Held and Soden 2006). It further follows that the change in the horizontal net transport of water vapour is also scaled by the $\mathrm{C}-\mathrm{C}$ relation (Held and Soden 2006). This will have important consequences for the net mass accumulation on the ice sheets as precipitation over the ice sheets is expected to increase accordingly.

The result is sensitive to horizontal resolution. A high horizontal and vertical resolution will provide a better description of both physical and dynamical processes as well as a more realistic topographical mapping of the ice sheets that will affect both accumulation (solid precipitation) and ablation (evaporation, sublimation and run-off). We will exemplify this by analyzing a series of climate model integrations for the present as well as for a future climate.

In Sect. 2 we will first try to show the principal ideas by means of a simple Gedankenexperiment and demonstrate how temperature and precipitation are likely to influence SMB in a warmer climate. In Sect. 3 we show some results from SMB calculation from a high-resolution version of the ECHAM5 model. Section 4, finally, contains a general discussion and comparison with other recent studies.

\section{Some General Consideration on the Mass Balance of Ice Sheets in a Warmer Climate}

Let us undertake a simple Gedankenexperiment in addressing the following question:

What will happen to the Earth's ice sheets if the global temperature increases by some $3^{\circ} \mathrm{C}$ ?

Let us assume at the outset that the ice sheets are in a quasi-equilibrium or that the imbalance is not caused by a temperature perturbation. This means that accumulation and ablation, at least when averaged over a period of time, are of the same magnitude. 
Furthermore, we will not consider any changes in iceberg discharges, but simply assume that these at first order are either neutral or proportional to any changes in the net surface mass balance. We use here 1.75 and $13.92 \mathrm{Mkm}^{2}$ for the ice-covered area of Greenland and Antarctica, respectively.

According to observations and model studies (Ohmura 2001), ablation can be estimated from the mean summer temperature over the ice using the empirical formula

$$
\begin{array}{cl}
\mathrm{A}=514 \mathrm{~T}_{\mathrm{JJA}}+930 & \text { if } \mathrm{T}_{\mathrm{JJA}}>-1.8^{\circ} \mathrm{C} \\
\mathrm{A}=0 & \text { if } \mathrm{T}_{\mathrm{JJA}}<-1.8^{\circ} \mathrm{C}
\end{array}
$$

Here $A$ is the total annual ablation $A\left(\mathrm{~mm} /\right.$ year) and $\mathrm{T}_{\mathrm{JJA}}$ is the mean summer temperature in ${ }^{\circ} \mathrm{C}$. For the southern hemisphere we use DJF, December, January and February instead. As a first step we need to estimate the size of the area where the summer temperature is higher than $-1.8^{\circ} \mathrm{C}$. For Antarctica, preliminary studies (Wild et al. 2003) indicate that the $-2^{\circ} \mathrm{C}$ isotherm for a comparative global warming to $3^{\circ} \mathrm{C}$ falls outside the Antarctic continent and consequently no significant ablation will occur. For Greenland on the other hand the area of ablation will increase. However, as has been shown by Wild et al. (2003) this must be estimated from detailed topographic data and not from lowresolution model topography.

The majority of present climate models, such as used in IPCC AR4, have a rather crude representation of the topography and are therefore in this respect highly misleading in representing steep slopes. A warming of some $3^{\circ} \mathrm{C}$ corresponds to a height difference of ca $400 \mathrm{~m}$ and using detailed topographic data that means that the melt zone of Greenland is increasing by some $10 \%$. This would correspond to a total increase in ablation according to expression (1) by some $2.71 \times 10^{14} \mathrm{~kg}$ or $271 \mathrm{~km}^{3} /$ year water. Using a topography representation (ca $100 \mathrm{~km}$ grid length) of a similar resolution as the climate model used in IPCC AR4 the melt zone area will lead to a higher ablation (Wild et al. 2003, their Figure 6).

As climate is warming the water vapour is increasing proportional to the ClausiusClapeyron relation (Pierrehumbert et al. 2007). It also follows that the change in the transport or net convergence of water vapour also scales with the $\mathrm{C}-\mathrm{C}$ relation, (Held and Soden 2006). For a $3{ }^{\circ} \mathrm{C}$ warming the net transport of water vapour is expected to increase by $20-25 \%$. Let us here use the lower value of $20 \%$. The annual mass accumulation (precipitationsublimation) of Greenland is estimated to $340 \mathrm{~mm} /$ year corresponding to some $600 \mathrm{~km}^{3} /$ year water. A $20 \%$ increase in net moisture convergence would then correspond to $120 \mathrm{~km}^{3} /$ year water. Together with the increase in ablation this will result in a mass loss for Greenland of $151 \mathrm{~km}^{3} /$ year corresponding to an increase in sea level rise by ca. $0.4 \mathrm{~mm} /$ year.

For Antarctica the situation is different. Here the ablation is insignificant and the corresponding mass increase of $20 \%$ (precipitation-sublimation) is equal to an increase in precipitation of ca $33 \mathrm{~mm} /$ year equal to $460 \mathrm{~km}^{3} /$ year water. The corresponding contribution to sea level would correspond to a fall of ca. $1.3 \mathrm{~mm} / \mathrm{year}$.

It is easily realized that the general issue is highly non-linear. If the warming were to increase further, the melt zone is likely to affect central areas of Greenland where the slope is much less and hence the melt zone would increase significantly faster. This would rapidly add to the negative mass balance leading to a further rise in sea level. Secondly, any further increase in warming is likely to extend ablation to some of the coastal regions of Antarctica. A more general interpretation can thus be done as follows.

For a modest warming we are likely to have a net mass accumulation as the source term increases more rapidly than the sink term. The ablation is further likely to be modest because the steep slopes of the glaciated areas. However, as soon as the warming has passed a critical value, that probably is higher than $+3^{\circ} \mathrm{C}$, the ablation will accelerate as 
the area exposed to melting is rapidly growing as it starts to affect the region of modest slope on Greenland. Gregory and Huybrechts (2006) have estimated critical values for Greenland to $4.5^{\circ} \mathrm{C} \pm 0.9^{\circ} \mathrm{C}$. A similar development is likely to occur at the Antarctic continent but would require a much larger proportional temperature increase.

So a general conclusion might be that in a climate warming scenario ice sheets might initially increase and consequently sea level will fall due to the fact that accumulation will increase faster than ablation. However, for a more substantial warming this is likely to turn into another regime dominated by rapid mass losses. Needless to say, the estimate must be corrected for an additional mass loss due to calving that in its turn is influenced by higher temperatures both in the atmosphere and in the oceans. In the next section we will contrast these general observations with actual calculations from a comprehensive climate model.

\section{Result of Recent Model Studies with the ECHAM5 Climate Model}

To realistically and credibly calculate the surface mass balance with a numerical model it requires not only a model that is physically and dynamically capable of reproducing the key processes that determine the surface mass balance. It also requires a model with sufficient resolution to represent the 3-dimensional form of the ice sheets and the way the ice sheets are influenced by the weather patterns as well as the way the ice sheets influence the weather patterns in their turn. It is only recently that global models at sufficient resolution have become available for climate change studies such as computing the SMB of the ice sheets on Greenland and Antarctica. Most previous studies have made use of imbedded regional models using the lateral boundary values of a global general circulation model. The advantage of using a high-resolution global model is to avoid artificial circulation at the boundaries between the global and regional model that might influence the water flux. Furthermore, the results of limited area models depend also on the global model that controls the net transport of water vapour through the boundary.

We show here some recent studies with the Max Planck Institute for Meteorology (MPIM) climate model ECHAM5 (Roeckner et al. 2003, 2006) but at a much higher resolution than was described in the original publications. Examples of high resolution studies by this model can be found in Bengtsson et al. (2007a) and (2009) and the reader is referred to these later publications for a description of the high resolution experiments. Data for precipitation, evaporation, ablation and SMB were calculated and systematically stored during the cause of the integrations. We have here used archived data for every month. Two kinds of studies are described.

The first study is a standardized numerical experiment using observed sea surface temperature, SST. Such experiments have been undertaken by the atmospheric modelling community to compare and evaluate models and are notified by the acronym, AMIP, Atmospheric Modelling Inter-comparison Project (AMIP 1996). To some degree AMIP experiments are constrained by the observed climate through the sea-surface-temperatures (SST) but only to a limited degree as the high and middle latitude circulation in particular is only weakly constrained by the SST.

The second study is a climate change experiment exploring how the ice sheets will respond to a warmer climate, in turn a consequence of an increasing greenhouse gas concentration and changing aerosols. Due to the use of different resolution in the experiments, the size of the ice sheets varies somewhat. In order to simplify the inter-comparison between the experiments undertaken here, as well as similar studies elsewhere, we have normalized the area size to $1.75 \mathrm{Mkm}^{2}$ for Greenland and $13.92 \mathrm{Mkm}^{2}$ for Antarctica. 


\subsection{Surface Mass Balance in the Present Climate}

In the first experiment we use a very high-resolution version of the ECHAM5 spectral transform model at a triangular truncation of T319, corresponding to a Gaussian grid of ca $40 \mathrm{~km}$. The model has been integrated through the 23 years (1979-2001) using observed sea surface temperatures, SST and other conditions, such as greenhouse gas concentration stipulated in the AMIP 2 protocol (AMIP 1996).

We compare the results with a similar integration at lower horizontal resolution. Figure 1 shows the topography of Greenland and Antarctica, respectively and for both T319 and T63. The T63 resolution is typical for the climate models used in IPCC AR4 (IPCC 2007). In Figure 2 we show a cross section in a West to East direction through Greenland at latitude $63^{\circ} \mathrm{N}$ and $73^{\circ} \mathrm{N}$. We have also indicated in the cross section the topography calculated from a $1 \times 1 \mathrm{~km}$ grid (DiMarzio et al. 2007). The cross section shows clearly that the T319 resolution follows the actual topography rather closely while the T63 is heavily smoothed.

(a)

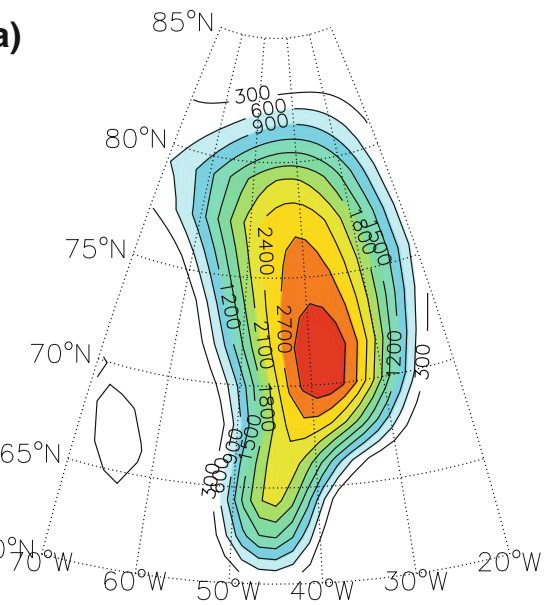

(c)

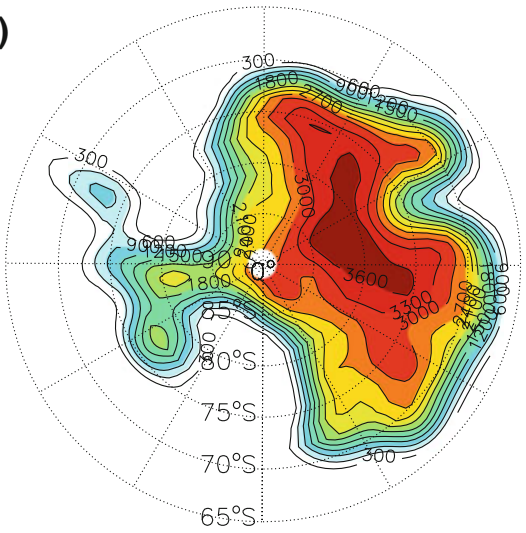

(b)
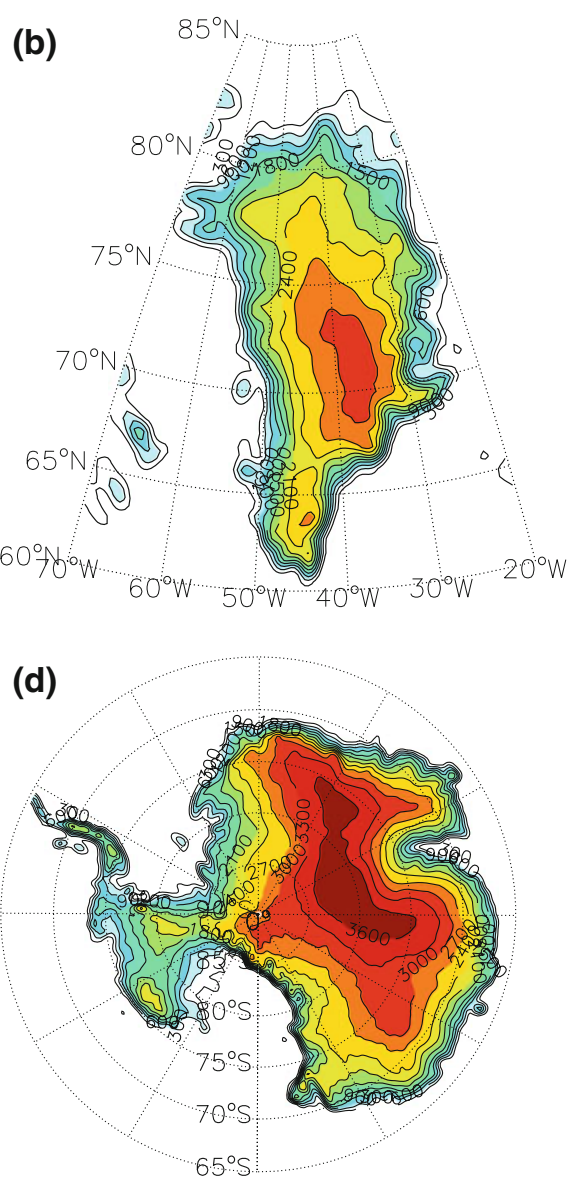

Fig. 1 Representation of the Greenland and Antarctica orography, for two model resolutions, T63 (a, c) and T319 (b, d). Values are expressed in meters (contour lines interval is $300 \mathrm{~m}$ ). Colors towards red denote high elevation 

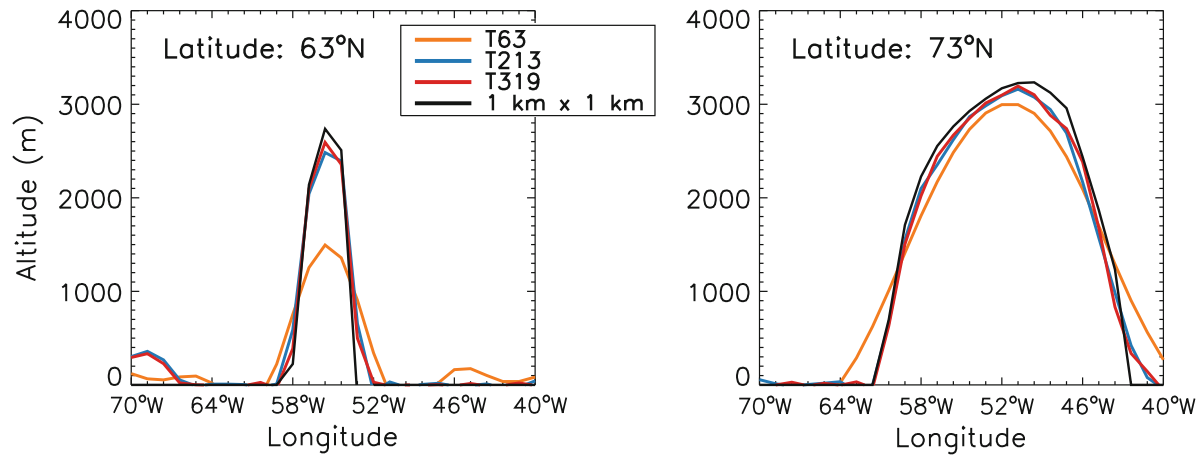

Fig. 2 Cross section in the West to East direction through Greenland at latitude $63^{\circ} \mathrm{N}$ (left) and $73^{\circ} \mathrm{N}$ (right), for various resolutions: T319 (red line), T213 (blue line), T63 (orange line) and $1 \times 1 \mathrm{~km}($ black line). Values are expressed in meters

Table 1 Greenland ice sheet; precipitation, ablation and surface mass budget (in $\mathrm{km}^{3} /$ year) for three horizontal resolutions

1978-2000 average

b 1978-1998 average

\begin{tabular}{llll}
\hline Parameter & T319 & T106 $^{\mathrm{b}}$ & T63 $^{\mathrm{b}}$ \\
\hline Precipitation & 746 & 778 & 861 \\
Snow & 626 & 660 & 723 \\
Ablation & 358 & 1,183 & 1,027 \\
SMB & 268 & -523 & -304 \\
Sea level change mm/year & -0.7 & 1.4 & 0.8 \\
\hline
\end{tabular}

We summarize the results for Greenland in Table 1 where we also for comparison include the results for the lower resolutions T106 and T63. Precipitation consists of some $85 \%$ of snow. It is larger for the lower resolutions presumably because the area of Greenland is distorted at the lower resolution due to the imperfect representation. Another explanation might be that synoptic weather systems that pass Greenland will be penetrating further inland in the lower resolution model. However, as can be seen, there is a considerable increase in the ablation at the lower resolution. We consider this to be a consequence of the artificial topography at the lower resolution as shown in Figure 2. This will strongly influence the SMB. The T319 resolution run shows a positive SMB of $268 \mathrm{~km}^{2} /$ year, implying a negative contribution to sea level height. The low-resolution runs on the other hand show a negative SMB because of a much larger ablation, and correspondingly a positive contribution to sea level change.

Table 2 shows similar results for Antarctica. At the T319 resolution 99\% of the precipitation on Antarctica is snow. At this resolution the ablation is small leading to a SMB of $2,601 \mathrm{~km}^{3}$. For the T63 resolution the ablation is significantly higher so in spite of higher precipitation, the SMB is reduced to $1,864 \mathrm{~km}^{3}$. The effect on sea level height is strongly negative. For the T319 run the increased accumulation will reduce the sea level height by $7.2 \mathrm{~mm} /$ year and $2 \mathrm{~mm} /$ year less for the T63 resolutions. Again we must recall that these values do not include any mass losses due to calving or to long-term adjustment processes.

We have also investigated the annual variability of SMB for Greenland and Antarctica, respectively, Figure 3. There are considerable variations from year to year due to the natural variability of atmospheric circulation with considerable inter-annual variations making it virtually impossible to obtain robust trends. The magnitude of the internal 
Table 2 Antarctica ice sheet; precipitation, ablation and surface mass budget (in $\mathrm{km}^{3} / \mathrm{year}$ ) for three model horizontal resolutions

\begin{tabular}{llll}
\hline Parameter & T319 & T106 $^{\mathrm{b}}$ & T63 $^{\mathrm{b}}$ \\
\hline Precipitation & 3,174 & 3,580 & 3,698 \\
Snow & 3,115 & 3,491 & 3,572 \\
Ablation & 514 & 1,627 & 1,778 \\
SMB & 2,601 & 1,864 & 1,794 \\
Sea level change mm/year & -7.2 & -5.2 & -5.0 \\
\hline
\end{tabular}

a 1978-2000 average

b 1978-1998 average
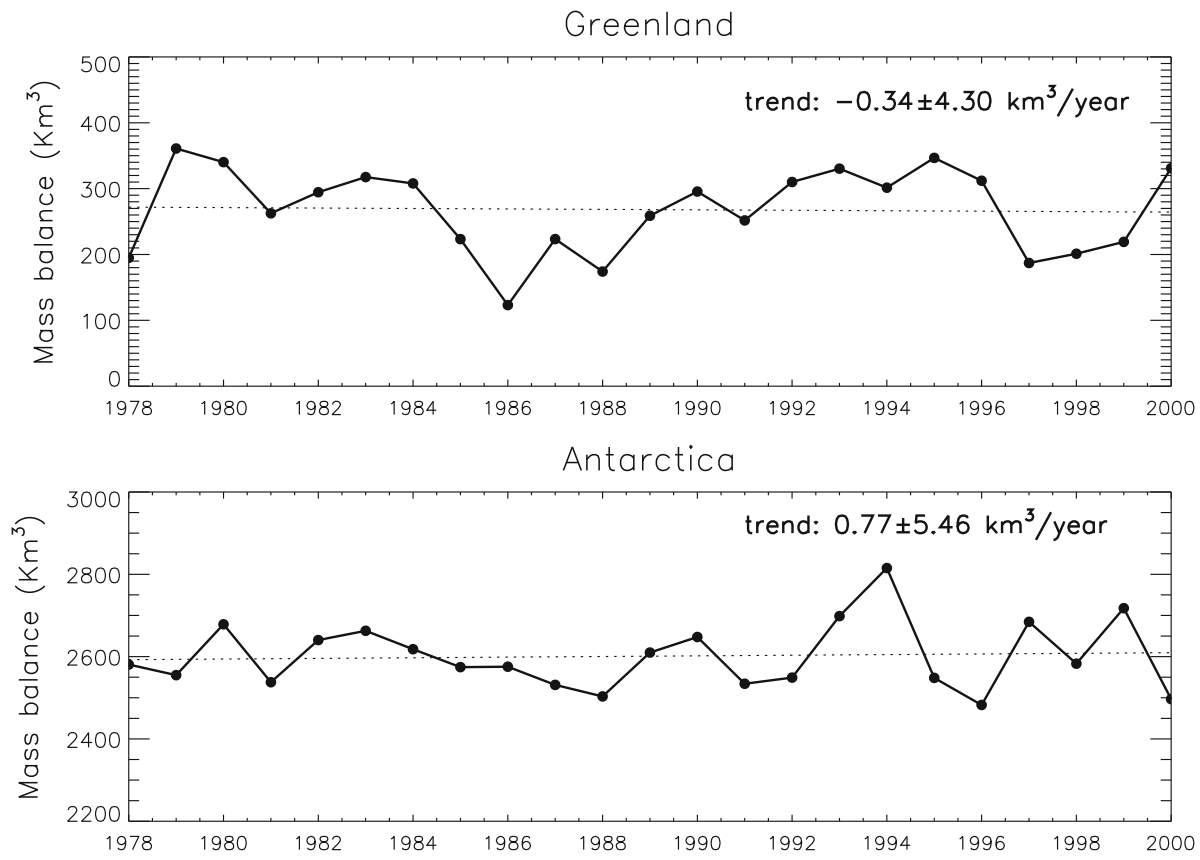

Fig. 3 Annual variability of SMB for Greenland and Antarctica. Values are in $\mathrm{km}^{3} /$ year

variability is close to the variability from observational assessment of SMB on Greenland (Johannessen et al. 2005). This must be kept in mind when interpreting observational records shorter than some 30 years.

\subsection{The Effect of Climate Change}

We will next consider results from the climate change experiment at T213 resolution (equivalent to ca $60 \mathrm{~km}$ grid). We compare two 30-year periods, one from the twentieth century (1960-1990), C20 and the other for the twenty-first century (2070-2100), C21 (Roeckner et al. 2006; Bengtsson et al. 2007a). For the period until year 2000 we have used 
observed greenhouse gases and estimated aerosol concentrations. After year 2000 the calculation is based on the IPCC SRES scenario A1B (IPCC 2007).

$\mathrm{A} 1 \mathrm{~B}$ is a middle of the range scenario with a $\mathrm{CO}_{2}$ increase growing to ca $60 \mathrm{Gton} / \mathrm{year}$ in 2050 (corresponding to an annual increase of $1.75 \%$. The annual increase 2000-2007 was more than twice as high). The sulphate aerosol emission reaches a maximum in 2020 and decreases thereafter relatively fast. At the end of the twenty-first century it is only some $30 \%$ of its maximum value. The calculated global temperature change at C20 and $\mathrm{C} 21$ amounts to $\mathrm{ca}+3^{\circ} \mathrm{C}$. The mean annual temperature change over Greenland increases by $5.2^{\circ} \mathrm{C}$ and over Antarctica by $3^{\circ} \mathrm{C}$ (Tables 3,4).

Numerical experiments show that the transport of water vapour into areas of general convergence scales with the $\mathrm{C}-\mathrm{C}$ relation. The increase in the net transport of moisture into the Arctic region $\left(60^{\circ} \mathrm{N}-90^{\circ} \mathrm{N}\right)$ amounts to $27 \%$ between $\mathrm{C} 20$ and $\mathrm{C} 21$ with a similar increase in (P-E). The corresponding net transport into the Antarctic region $\left(60^{\circ} \mathrm{S}-90^{\circ} \mathrm{S}\right)$ is slightly smaller, amounting to $22 \%$. For further information see Bengtsson et al. (2011).

As discussed by Held and Soden (2006) regional precipitation in areas of convergence follows the transport. Specifically over Greenland calculation shows that precipitation is increasing by $33 \%$ (Table 3) and over Antarctica by $18 \%$ (Table 4).

The left panel of Figure 4 shows the annual precipitation for Greenland at C20 with the marked maximum precipitation in the southeastern part of the island, in agreement with different observational estimates (Ohmura et al. 1999). Figure 4 (right panel) shows the percentage change in precipitation between C21 and C20. Precipitation increases everywhere with the largest percentage contribution in the northeastern part. This is expected to be related to a change in cyclonic activity and reduced Arctic sea ice (Bengtsson et al. 2009).

Figure 5 shows the same for Antarctica. There are huge variations in precipitation between different parts of Antarctica, with comparatively high precipitation near the coast and at the western part of the Antarctic Peninsula. In the high altitude inner part of

Table 3 Greenland; mean temperature, precipitation, ablation and surface mass balance changes (in $\mathrm{km}^{3} /$ year) at $\mathrm{C} 20$ (1960-1990) and C21 (2070-2100) and the corresponding changes

\begin{tabular}{llll}
\hline Parameter & $\mathrm{T} 213(\mathrm{C} 20)$ & $\mathrm{T} 213(\mathrm{C} 21)$ & $\mathrm{C} 21-\mathrm{C} 20$ \\
\hline Temperature & $-21.8^{\circ} \mathrm{C}$ & $-16.6^{\circ} \mathrm{C}$ & $5.2^{\circ} \mathrm{C}$ \\
Precipitation & 714 & 946 & $232(33 \%)$ \\
Snow & 619 & 691 & $72(12 \%)$ \\
Ablation & 281 & 848 & 567 \\
SMB & 338 & -157 & -495 \\
Sea level change mm/year & -0.9 & +0.4 & +1.4 \\
\hline
\end{tabular}

Table 4 Antarctica; mean temperature, precipitation, ablation and surface mass balance changes (in $\mathrm{km}^{3} /$ year) at C20 (1960-1990) and C21 (2070-2100) and the corresponding changes

\begin{tabular}{llll}
\hline Parameter & T213(C20) & T213(C21) & C21-C20 \\
\hline Temperature & $-38.5^{\circ} \mathrm{C}$ & $-35.5^{\circ} \mathrm{C}$ & $3^{\circ} \mathrm{C}$ \\
Precipitation & 3,182 & 3,769 & $587(18 \%)$ \\
Snow & 3,137 & 3,624 & $487(16 \%)$ \\
Ablation & 583 & 785 & 202 \\
SMB & 2,554 & 2,839 & 285 \\
Sea level change mm/year & -7.0 & -7.9 & -0.8 \\
\hline
\end{tabular}



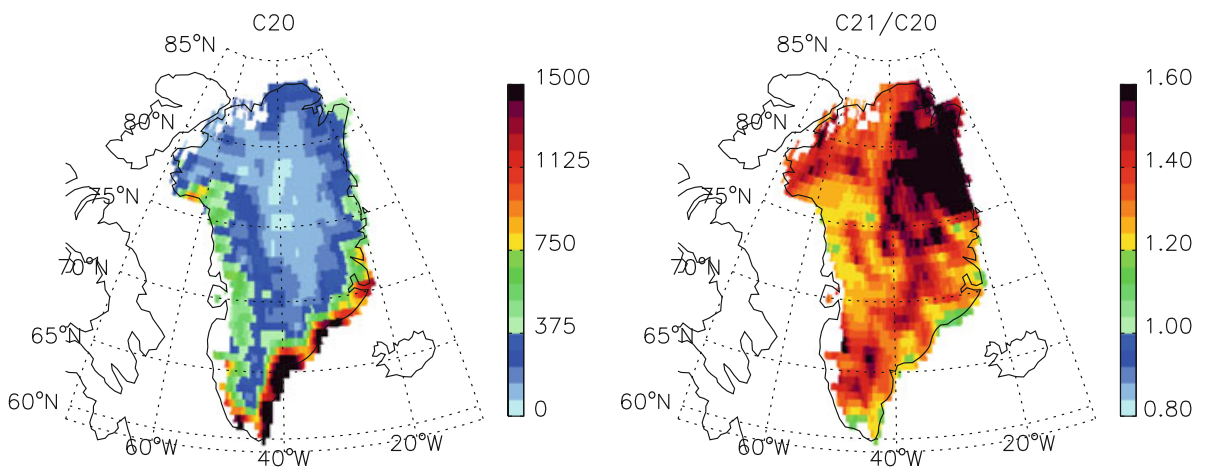

Fig. 4 Annual precipitation for Greenland for the C20 experiment (left) and percentage change between the $\mathrm{C} 21$ and C20 experiments (right). Values are in $\mathrm{mm} / \mathrm{year}$
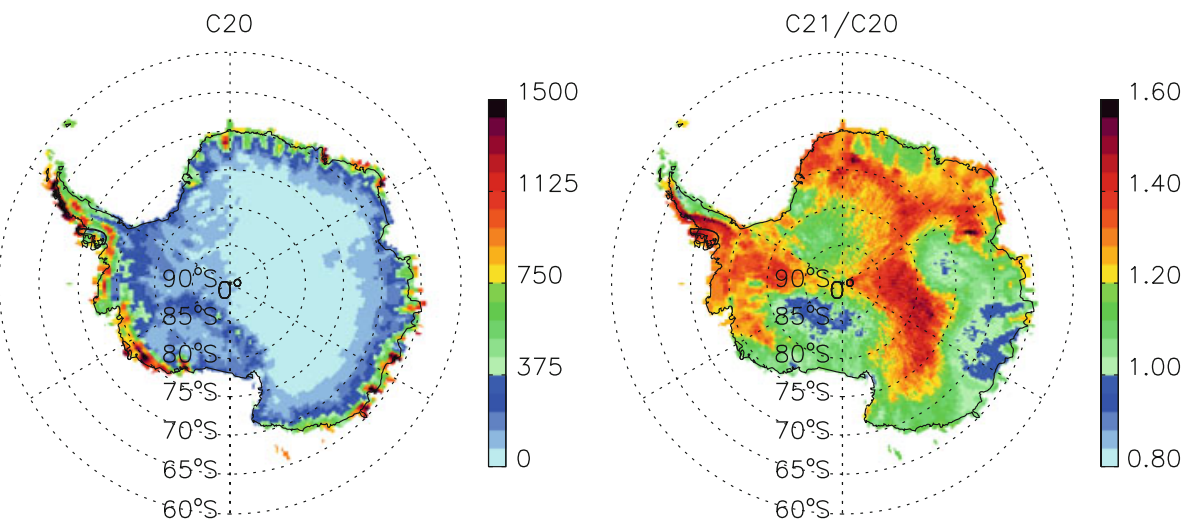

Fig. 5 Same as Figure 4 but for Antarctica

Antarctica, the precipitation is as low as $10-20 \mathrm{~mm} /$ year and difficult to estimate. Using recent re-analysis data from ECMWF ERA-Interim (Dee and Uppala 2009) we found a mean annual net moisture transport for an area over East Antarctica (a circular region of $8^{\circ}$ radius in geodetic coordinates with its centre at $81^{\circ} \mathrm{S}, 60^{\circ} \mathrm{E}$ ) as low as $2 \mathrm{~mm} / \mathrm{month}$. This is in general agreement with other estimates (Bromwich et al. 2004).

The somewhat irregular percentage change in precipitation between C20 and C21 (right panel of Figure 5) is probably a model artefact as we are comparing very low values in precipitation. As described in Bengtsson et al. (2006) the change in the climate of the southern polar region is a tendency for the storm tracks to move closer to the Antarctic continent. It was suggested that this is related to the poleward transition of the area of maximum SST gradient leading to a poleward transition of the area of maximum baroclinicity (Bengtsson et al. 2006).

Table 3 summarizes the mean mass balance for Greenland for C20 and C21. Precipitation increases by $33 \%$ while the increase for solid precipitation is much less by $12 \%$. This indicates that an increasing amount of precipitation at C21 falls as rain on Greenland thus leading to a large increase in the ablation. The change in SMB is $-495 \mathrm{~km}^{3} /$ year corresponding to a sea level rise of $1.4 \mathrm{~mm} /$ year. As shown in Figure 6a, the largest negative 

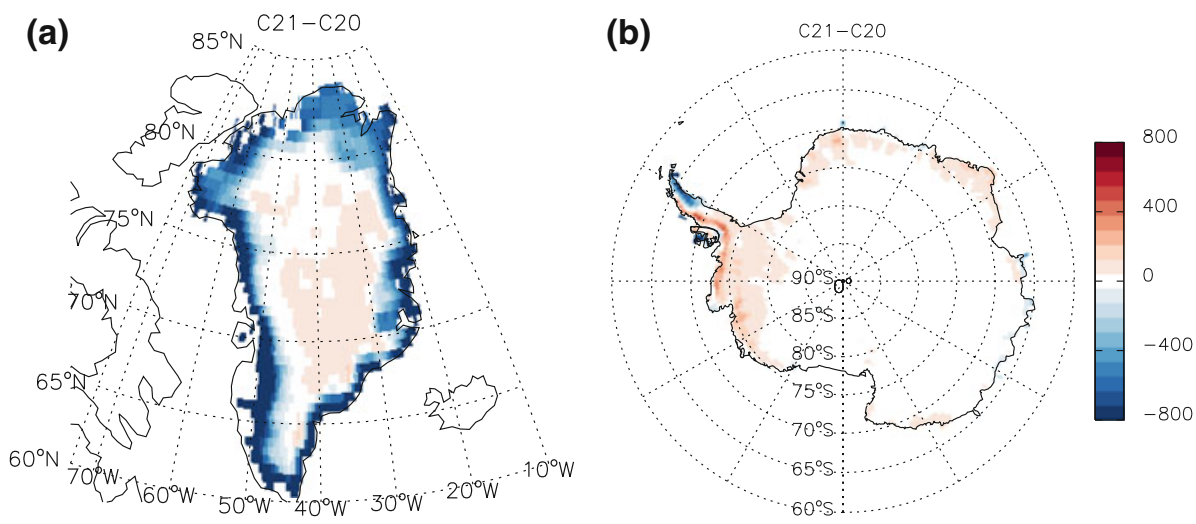

Fig. 6 a Shows the annual change in SMB for Greenland between C21 and C20 and b the same for Antarctica. Note the difference between the coastal regions (surface mass losses) and the interior (surface mass gains). Unit: $\mathrm{mm} / \mathrm{year}$

change in SMB is located at the ablation zones close to the ice sheet margin and, especially in the southern part, in agreement with Mernild et al. (2010). The inner parts of the ice sheets have a positive SMB.

Based on the GLAS/ICES at $1 \mathrm{~km}$ laser altimetry digital elevation model of Greenland (DiMarzio et al. 2007) and assuming that the upper limit of the ablation zone is increasing linearly from 850 to $1,500 \mathrm{~m}$ a.s.l. from the North to the South of Greenland, the mean width of the ablation zone is found to be $313 \mathrm{~km}$, ranging from $6 \mathrm{~km}$ to $1,590 \mathrm{~km}$. Consequently, the model may still overestimate the ablation zone even at the T213 resolution, which corresponds approximately to $60 \mathrm{~km}$.

Table 4 shows the mass balance for Antarctica at C20 and C21. The increase in precipitation is less than for Greenland (18\%) and the dominant part of precipitation at C21 will still fall as snow. The increase in ablation is less than the increase in solid precipitation so the SMB is positive. The change in SMB is $+285 \mathrm{~km}^{3} /$ year corresponding to a sea level fall by $0.8 \mathrm{~mm} /$ year. At the northern and eastern part of the Antarctic Peninsula though, we find some increased net loss, as shown by the negative SMB (Figure 6b). Similar increases in melting over this region have also been found by Krinner et al. (2007) with the LMDZ4 model.

We have undertaken similar calculations with the T63-resolution model. Individual values differ as both precipitation and ablation are larger, but interestingly enough the change in SMB or sea level change is more or less the same. This suggests that the calculated change might be robust to resolution changes even if the data for each period differ significantly. Presently we do not know if this is a coincidence or an indication that climate change as a perturbation study can be accomplished with simpler models.

Figure 7 shows the inter-annual variation in SMB for both C20 and C21. The red lines show results for Greenland. While there is a distinct difference between the two curves it is not possible to identify a robust trend in the present climate run due to the dominance of strong inter-annual variations in the atmospheric circulation and hence in both temperature and precipitation. On the contrary, in the warmer climate scenario, the SMB trend over Greenland is strongly negative (around $-10.7 \mathrm{~km}^{3} /$ year).

We have also included in Figure 7 the change in SMB for northern hemisphere $(\mathrm{NH})$ glaciers outside Greenland. These glaciers cover an area equal to $550 \times 10^{3} \mathrm{~km}^{2}$ (Ohmura 


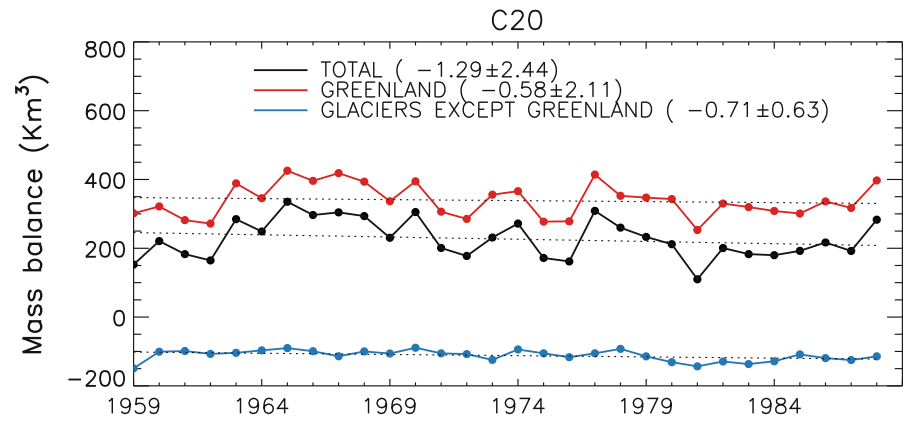

C21

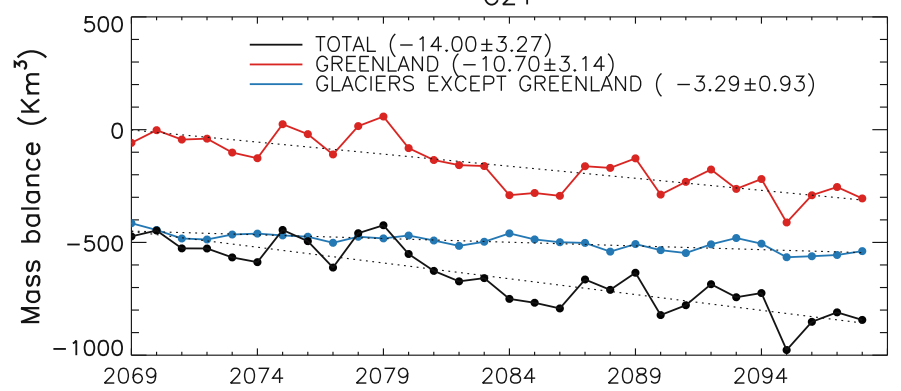

Fig. 7 Annual variability and linear trends of SMB for the C20 (top panel) and C21 (bottom panel) experiments for the Greenland ice sheet (red line), for the northern hemisphere glaciers outside Greenland (blue line) and the sum of the two (black line). Values are in $\mathrm{km}^{3} /$ year

2006). As previously, we normalize the simulated glaciated area to this value for comparison purposes. Over these glaciers, SMB is negative for the C20 as well with an indication of a slight negative trend. The average SMB for the C20 period (1959-1989) is $-112 \mathrm{~km}^{3} /$ year, which is a bit lower than observational estimates, e.g., $-140 \mathrm{~km}^{3} /$ year (Ohmura 2006).

The contribution of the $\mathrm{NH}$ glaciers outside Greenland to the total northern hemisphere SMB is significant, especially in the $\mathrm{C} 21$ run, reducing the SMB by $523 \mathrm{~km}^{3} /$ year on average (blue line, Figure 7). The change in SMB over these glaciers between C20 and C21 is equal to $-404 \mathrm{~km}^{3} /$ year. This leads to a total NH SMB change of $-900 \mathrm{~km}^{3} /$ year, which corresponds to a sea level rise of $+2.7 \mathrm{~mm} /$ year.

\section{Results from Other Model Studies}

A series of papers during the last decade has undertaken different estimates of the total mass losses on Greenland (Mernild et al. 2010 and references therein). We summarize a number of these studies in Table 5. During the last decade or decades these data estimate the surface mass balance changes to between 200 and $400 \mathrm{~km}^{3} /$ year and generally smaller during the last 5-8 years. There are also estimates of changes in the surface melt area. According to Mote (2007) this was found to have increased by 1\%/year during the period 1973-2007 corresponding to an increase in the melt area by some $35 \%$ of the whole of Greenland between 1973 and 2007. Other estimates are going even further. Tedesco (2007) for example suggests an increase in the melt area by some 32\% for the period 1992-2005. 
Table 5 Precipitation and SMB estimates (in $\mathrm{km}^{3} /$ year) for the Greenland ice sheet from recent studies. After Mernild et al. (2010)

\begin{tabular}{llllll}
\hline $\begin{array}{l}\text { Parameter } \\
\left(\mathrm{km}^{3} / \text { year }\right)\end{array}$ & $\begin{array}{l}\text { Box et al. } \\
(2006)\end{array}$ & $\begin{array}{l}\text { Fettweis } \\
(2007)\end{array}$ & $\begin{array}{l}\text { Hanna et al. } \\
(2008)\end{array}$ & $\begin{array}{l}\text { Mernild et al. } \\
(2009)\end{array}$ & $\begin{array}{l}\text { This study } \\
\text { T319 }\end{array}$ \\
$\begin{array}{l}\text { Studied period } \\
1995-2004\end{array}$ & $1979-2006$ & $1995-2007$ & $1995-2007$ & $1978-2000$ \\
\hline Precipitation & $654 \pm 61$ & $641 \pm 60$ & $655 \pm 54$ & $636 \pm 35$ & $746 \pm 76$ \\
SMB & $160 \pm 69$ & $263 \pm 138$ & $316 \pm 116$ & $141 \pm 85$ & $268 \pm 64$ \\
\hline
\end{tabular}

At the same time the longer term warming trend has been more modest. Box et al. (2009), combining meteorological stations' records and regional climate model output, have estimated the summertime temperature change over Greenland to be about $0.7^{\circ} \mathrm{C}$ from 1955 to 2007. This would correspond to a lifting of say the $-2^{\circ} \mathrm{C}$ isotherm by ca $100 \mathrm{~m}$. Using the methods by Wild et al. (2003) (see their Figure 6) this would correspond to a miniscule increase in the area of melting. How can we then explain this apparent inconsistency?

According to Box et al. (2009) and Hanna et al. (2008), the mean annual temperature was broadly constant from the 1950 s to the mid 1990 s and increased rapidly by $1-2^{\circ} \mathrm{C}$ thereafter. This suggests that according to Ohmura's empirical relation no ablation might be expected above some $1,200 \mathrm{~m}$ asl in the present climate. It is also clear that the many warm summers during the last 15 years are likely to have led to an increased ablation in levels generally below $1,200 \mathrm{~m}$. However, there is no evidence from present climate models that the sharp warming trend over the last decade or so can be extrapolated. As can also be seen on both Figs. 3 and 6 there are considerable inter-annual variations that might create fortuitous trends on decadal time-scales.

We have compared our climate change results with other groups' results for Greenland and Antarctica, respectively, Tables 6 and 7. The results for Greenland is similar to Mernild et al. (2010) but cannot be exactly compared as the period of comparison differs. Wild et al. (2003) finds a positive SMB change with ECHAM4 (T106 grid), but with a $2 \times \mathrm{CO}_{2}$ climate scenario. Over Antarctica, we find a somewhat lower increase in the

Table 6 Precipitation and SMB estimates comparison for the climate scenarios for Greenland

\begin{tabular}{|c|c|c|c|c|c|c|}
\hline \multirow[t]{2}{*}{ Reference } & \multicolumn{3}{|c|}{ Precipitation } & \multicolumn{3}{|c|}{ SMB } \\
\hline & $\mathrm{C} 20$ & $\mathrm{C} 21$ & Change & $\mathrm{C} 20$ & $\mathrm{C} 21$ & Change \\
\hline Wild et al. (2003) $\left(2 \times \mathrm{CO}_{2}\right)$ & 670 & 873 & $203(30 \%)$ & 579 & 740 & $161(28 \%)$ \\
\hline Mernild et al. (2010) (C21: 2050-2080) & 646 & 741 & $95(15 \%)$ & 219 & -59 & $-278(-127 \%)$ \\
\hline This study (C21: 2070-2100) & 714 & 946 & $232(33 \%)$ & 338 & -157 & $-495(-146 \%)$ \\
\hline
\end{tabular}

Table 7 Precipitation and SMB estimates comparison for the climate scenarios for Antarctica

\begin{tabular}{|c|c|c|c|c|c|c|}
\hline \multirow[t]{2}{*}{ Reference } & \multicolumn{3}{|c|}{ Precipitation } & \multicolumn{3}{|l|}{ SMB } \\
\hline & $\mathrm{C} 20$ & $\mathrm{C} 21$ & Change & $\mathrm{C} 20$ & $\mathrm{C} 21$ & Change \\
\hline Wild et al. (2003) $\left(2 \times \mathrm{CO}_{2}\right)$ & 2,617 & 2,965 & $348(13 \%)$ & 2,311 & 2,617 & $+306(13 \%)$ \\
\hline Krinner et al. (2007) (C21: 2050-2080) & 2,282 & 2,770 & $488(21 \%)$ & 2,102 & 2,547 & $+445(21 \%)$ \\
\hline This study (C21: 2070-2100) & 3,182 & 3,769 & $587(18 \%)$ & 2,554 & 2,839 & $+285(11 \%)$ \\
\hline
\end{tabular}


Antarctic SMB than Krinner et al. (2007). The reason for this is not clear but could be due to a tendency of the ECHAM5 model to simulate too high orographic precipitation as discussed by Hagemann et al. (2006). However, as pointed out previously, precipitation is to a large extent unknown in large parts of Antarctica. Present estimates from global models, reanalysis data and dynamical retrieval methods, range from 2,310 to $3,202 \mathrm{~km}^{3}$ / year (Bromwich et al. 2004) which means that the data from Krinner et al. (2007) is at the lower end, while the ECHAM5 used in our study is at the upper end.

\section{Concluding Remarks}

Mass changes on the ice sheets are due to processes covering a wide range of time scales from tens of thousand years to events such as massive losses of ice shelf that can occur in short time events such as the Larsen shelf ice in 2002 (De Angelis and Skvarca 2003). A realistic assessment of mass losses of the ice sheets must therefore take into consideration processes related to the internal dynamics of the ice. Considerable progress is taking place here as reported elsewhere (Mernild et al. 2009; Ridley et al. 2005; Gregory and Huybrechts 2006) and other publications in this issue.

Let us return to the simple theoretical estimate in Sect. 2 compared to the recent model results discussed in Sect. 3. The SMB results for Greenland are larger by a factor of three from the estimate of the Gedankenexperiment, Table 8. There are several reasons for this. The model shows a larger ablation than the empirical estimate. There are several explanations for this. First, we might expect that ablation in a warmer climate will occur outside the summer season implying a larger total ablation. An examination of the model experiment shows that this is the case. Secondly, we note that the temperature change for Greenland actually is larger that the global average of $3^{\circ} \mathrm{C}$ by more than $2^{\circ} \mathrm{C}$. Thirdly, because of the higher temperature the area exposed to melting will increase more rapidly as we are entering a region with reduced slope. Finally, the accumulation is also slightly overestimated as the solid precipitation is increasing much less than the total precipitation.

For Antarctica the simple estimate in the Gedankenexperiment is in broad agreement with the model result except that the model calculation has a small ablation, giving rise to a reduction in the SMB. There is also a compensating effect in the accumulation as the model compared to our simple estimate has higher precipitation but a smaller percentage increase.

As discussed above the present result from the ECHAM5 model is close to what has been achieved with other general circulation models suggesting an accelerated mass loss at Greenland and a minor gain on Antarctica (Huybrechts et al. 2011). The contribution to sea level rise, if we assume a linear decrease in SMB during the twenty-first century, will amount to some $7.5 \mathrm{~cm}$ in sea level rise and from Antarctica a fall of some $4 \mathrm{~cm}$. This

Table 8 Comparison of precipitation, ablation and SMB as estimated in Sect. 2 and model results from Sect. 3

\begin{tabular}{lllll}
\hline $\begin{array}{l}\text { Parameter/Mass changes } \\
\text { in } \mathrm{km}^{3} / \text { year }\end{array}$ & $\begin{array}{l}\text { Estimate } \\
\text { (Greenland) }\end{array}$ & $\begin{array}{l}\text { Model } \\
\text { (Greenland) }\end{array}$ & $\begin{array}{l}\text { Estimate } \\
\text { (Antarctica) }\end{array}$ & $\begin{array}{l}\text { Model } \\
\text { (Antarctica) }\end{array}$ \\
\hline Precipitation & 120 & 232 & 460 & 587 \\
Ablation & 271 & 567 & 0 & 202 \\
SMB & -151 & -495 & 460 & 285 \\
Sea level change mm/years & +0.4 & +1.4 & -1.3 & -0.8 \\
\hline
\end{tabular}


result suggests that the problems for the twenty-first century are not the changes in SMB, that are likely to be minor, but rather other aspects of land ice losses such as a possible increase in calving caused by accelerating glaciers on the ice sheets. No doubt such questions will have to be addressed in a comprehensive way in future studies.

Acknowledgments The authors are most grateful to Noel Keenlyside of the Leibniz Institute of Marine Sciences at Kiel University for providing the ECHAM5 C20 and C21 climate simulation data.

\section{References}

Allerup P, Madsen H, Vejen F (2000) Correction of precipitation based on off-site weather information. Atmos Res 53(4):231-250

AMIP Project Office (1996) AMIP II Guidelines, AMIP newsletter, No. 8. Available online at http://wwwpcmdi.1lnl.gov/projects/amip/NEWS/amipn18.php\#2.\%20AMIP\%20II\%20Experimental

Bengtsson L, Hodges KI, Roeckner E (2006) Storm tracks and climate change. J Climate 19(15):3518-3543

Bengtsson L, Hodges KI, Esch M, Keenlyside N, Kornblueh L, Luo J, Yamagata T (2007a) How may tropical cyclones change in a warmer climate? Tellus 59(4):539-561

Bengtsson L et al (2007b) The need for a dynamical climate reanalysis. Bull Amer Meteor Soc 88:495-501

Bengtsson L, Hodges KI, Keenlyside N (2009) Will extra-tropical storms intensify in a warmer climate? J Climate 2276-2301:2009

Bengtsson L, Hodges KI, Koumoutsaris S, Zahn M, Keenlyside N (2011) On the atmospheric water balance of the Polar Regions. Tellus, under review

Box JE, Bromwich DH, Veenhuis BA, Bai LS, Stroeve JC, Rogers JC, Steffen K, Haran T, Wang SH (2006) Greenland ice sheet surface mass balance variability (1988-2004) from calibrated Polar MM5 output. J Climate 19(12):2783-2800

Box JE, Yang L, Bromwich D, Bai L-S (2009) Greenland ice sheet surface air temperature variability: 1840-2007. J Climate 22(14):4029

Bromwich DH, Guo Z, Bai L, Chen Q-S (2004) Modeled Antarctic precipitation. Part I: spatial and temporal variability. J Climate 17:427-447

De Angelis H, Skvarca P (2003) Glacier surge after ice shelf collapse. Science 299(5612):1560-1562

Dee DP, Uppala S (2009) Variational bias correction of satellite radiance data in the era-interim reanalysis. Q J R Meteorol Soc 135(644):1830-1841

DiMarzio J, Brenner A, Schutz R, Shuman CA, Zwally HJ (2007) GLAS/ICESat 1 km laser altimetry digital elevation model of Greenland. National Snow and Ice Data Center. Digital media, Boulder, Colorado

Fettweis X (2007) Reconstruction of the 1979-2006 Greenland ice sheet surface mass balance using the regional climate model MAR. Cryosphere 1(1):21-40

Gregory JM, Huybrechts P (2006) Ice-sheet contributions to future sea-level change. Philos Trans R Soc A-Math Phys Eng Sci 364(1844):1709-1731

Groisman PY, Peck EL, Quayle RG (1999) Intercomparison of recording and standard nonrecording US Gauges. J Atm Ocean Tech 16(5):602-609

Hagemann S, Arpe K, Roeckner E (2006) Evaluation of the hydrological cycle in the ECHAM5 model. J Climate 19(16):3810-3827

Hanna E, Huybrechts P, Steffen K, Cappelen J, Huff R, Shuman C, Irvine-Fynn T, Wise S, Griffiths M (2008) Increased runoff from melt from the Greenland ice sheet: a response to global warming. J Climate 21(2):331-341

Held IM, Soden BJ (2006) Robust responses of the hydrological cycle to global warming. J Climate 19(21):5686-5699

Huybrechts P, Goelzer H, Janssens I, Driesschaert E, Fichefet T, Goosse H, Loutre M-F (2011) Response of the Greenland and Antarctic ice sheets to multi-millennial greenhouse warming in the Earth system model of intermediate complexity LOVECLIM. Surv Geophys (this issue)

Intergovernmental Panel on Climate Change (IPCC) (2007) Climate change 2007: the scientific basis. Cambridge University Press, Cambridge

Jakobson E, Vihma T (2009) Atmospheric moisture budget in the Arctic based on the ERA-40 reanalysis Int J Climatol. doi:10.1002/joc.2039

Johannessen OM, Khvorostovsky K, Miles MW, Bobylev LP (2005) Recent ice-sheet growth in the interior of Greenland. Science 310(5750):1013-1016 
Krinner G, Magand O, Simmonds I, Genthon C, Dufrense J-L (2007) Simulated Antarctic precipitation and surface mass balance at the end of the twentieth and twenty-first centuries. Clim Dyn 28:215-230. doi: 10.1007/s00382-006-0177-X

Lemke P, Ren J, Alley RB, Allison I, Carrasco J, Flato G, Fujii Y, Kaser G, Mote P, Thomas RH, Zhang T (2007) Observations: changes in snow, ice and frozen ground. In: Solomon S, Qin D, Manning M, Chen Z, Marquis M, Averyt KB, Tignor M, Miller HL (eds) Climate change 2007: the physical science basis. Contribution of Working Group I to the fourth assessment report of the intergovernmental panel on climate change. Cambridge University Press, Cambridge, UK and New York

Mernild SH, Liston GE, Hiemstra CA, Steffen K, Hanna E, Christensen JH (2009) Greenland ice sheet surface mass-balance modelling and freshwater flux for 2007, and in a 1995-2007 perspective. Hydrol Process 23(17):2470-2484

Mernild SH, Liston GE, Hiemstra CA, Christensen JH (2010) Greenland ice sheet surface mass-balance modeling in a 131-yr perspective, 1950-2080. J Hydrometeorol 11(1):3-25

Mote TL (2007) Greenland surface melt trends 1973-2007: evidence of a large increase in 2007, Geophys Res Lett 34. doi:10.1029/2007GL031976

Oerlemans J (1990) A model for the surface balance of glaciers. Part 1: Alpine glaciers. Z Gletscherk Glazialgeol 27:63-83

Ohmura A (2001) Physical basis for the temperature-based melt-index method. J Appl Meteorol 40(4): $753-761$

Ohmura A (2006) Changes in mountain glaciers and ice caps during the twentieth century. Ann Glaciol 43:361-368

Ohmura A, Wild M, Bengtsson L (1996) A possible change in mass balance of Greenland and antarctic ice sheets in the coming century. J Climate 9(9):2124-2135

Ohmura A, Calanca P, Wild M, Anklin M (1999) Precipitation, accumulation and mass balance of Greenland ice sheet (1999). Z Gletscherk Glazialgeol 35:1-20

Pierrehumbert RT, Brogniez H, Roca R (2007) On the relative humidity of the Earth's atmosphere. In: Schneider T, Sobel AH (eds) The global circulation of the atmosphere. Princeton University Press, Princeton, NJ, pp 143-185

Ridley JK, Huybrechts P, Gregory JM, Lowe JA (2005) Elimination of the Greenland ice sheet in a high $\mathrm{CO}_{2}$ climate. J Climate 18(17):3409-3427

Roeckner E, Bauml G, Bonaventura L, Brokopf R, Esch M, Giorgetta M, Hagemann S, Kirchner I, Kornblueh L, Manzini E, Rhodin A, Schlese U, Schulzweida U, Tompkins A (2003) The atmospheric general circulation model ECHM5: Part 1, Tech Rep 349, Max Planck Institute for Meteorology, Hamburg

Roeckner E, Stier P, Feichter J, Kloster S, Esch M, Fischer-Bruns I (2006) Im-pact of carbonaceous aerosol emissions on regional climate change. Clim Dyn 27(6):553-571

Serreze MC, Barrett AP, Slater AG, Woodgate RA, Aagaard K, Lammers RB, Steele M, Moritz R, Meredith M, Lee CM (2006) The large-scale freshwater cycle of the arctic. J Geophys Res-Oceans 111(C11). doi:10.1029/2005JC003424

Tedesco M (2007) Snowmelt detection over the Greenland ice sheet from SSM/I brightness temperature daily variations. Geophys Res Lett 34. doi:10.1029/2006GL028466

Wild M, Calanca P, Scherrer SC, Ohmura A (2003) Effects of polar ice sheets on global sea level in highresolution greenhouse scenarios. J Geophys Res-Atmos 108(D5). doi:10.1029/2002JD002451 